\title{
Increased Serotonin Transporter Expression Reduces Fear and Recruitment of Parvalbumin Interneurons of the Amygdala
}

\author{
Marco Bocchio', Giulia Fucsina', Lydia Oikonomidis ${ }^{1,2,3,4}$, Stephen B McHugh ${ }^{3}$, David M Bannerman ${ }^{3}$, \\ Trevor Sharp ${ }^{2}$ and Marco Capogna*,I \\ 'MRC Brain Network Dynamics Unit, Department of Pharmacology, University of Oxford, Oxford, UK; '2Department of Pharmacology, University of \\ Oxford, Oxford, UK; ${ }^{3}$ Department of Experimental Psychology, University of Oxford, Oxford, UK
}

\begin{abstract}
Genetic association studies suggest that variations in the 5-hydroxytryptamine (5-HT; serotonin) transporter (5-HT) gene are associated with susceptibility to psychiatric disorders such as anxiety or posttraumatic stress disorder. Individuals carrying high 5-HTT-expressing gene variants display low amygdala reactivity to fearful stimuli. Mice overexpressing the 5-HTT (5-HTTOE), an animal model of this human variation, show impaired fear, together with reduced fear-evoked theta oscillations in the basolateral amygdala (BLA). However, it is unclear how variation in 5-HTT gene expression impacts on the microcircuitry of the BLA to change behavior. We addressed this issue by investigating the activity of parvalbumin (PV)-expressing interneurons (PVINs), the biggest IN population in the basal amygdala (BA). We found that increased 5-HTT expression impairs the recruitment of PVINs (measured by their c-Fos immunoreactivity) during fear. Ex vivo patch-clamp recordings demonstrated that the depolarizing effect of $5-\mathrm{HT}$ on PVINs was mediated by $5-\mathrm{HT}_{2 \mathrm{~A}}$ receptor. In 5-HTTOE mice, 5-HT-evoked depolarization of PVINs and synaptic inhibition of principal cells, which provide the major output of the $\mathrm{BA}$, were impaired. This deficit was because of reduced 5- $\mathrm{HT}_{2 \mathrm{~A}}$ function and not because of increased 5-HT uptake. Collectively, these findings provide novel cellular mechanisms that are likely to contribute to differences in emotional behaviors linked with genetic variations of the 5 -HTT.

Neuropsychopharmacology (2015) 40, 30 I5-3026; doi: I0.1038/npp.20I5.I57; published online 8 July 2015
\end{abstract}

\section{INTRODUCTION}

Linking genes and neural circuits to understand individual differences in emotional behavior and, ultimately, susceptibility to psychiatric disorders are a growing challenge in biological psychiatry. The 5-hydroxytryptamine transporter (5-HTT) is the key controller of the clearance of 5-hydroxytryptamine (5-HT; serotonin) from the synaptic cleft (Blakely et al, 1994), and represents the primary target for the pharmacological treatment of mood and anxiety disorders (Ballenger, 1999). The large natural variation in 5HTT expression in the human population, up to sevenfold between individuals (Lundberg et al, 2007), may in part be genetically driven (Hu et al, 2006; Lesch et al, 1996; Murphy et al, 2013). Several common variants of the human 5-HTT gene putatively determine 5-HTT expression levels, and have been linked to alterations in emotionality. Of particular interest is a $44 \mathrm{bp}$ insertion/deletion mutation in the 5-HTT gene promoter region (known as the 5-HTT gene linked to

*Correspondence: Professor M Capogna, MRC Brain Network Dynamics Unit, Department of Pharmacology, University of Oxford, Mansfield Road, Oxford OXI 3TH, UK, Tel: +44 I865 27I897, Fax: +44 I865 27I647, E-mail: marco.capogna@pharm.ox.ac.uk

${ }^{4}$ Current address: Department of Physiology, Development and Neuroscience, University of Cambridge, UK.

Received 30 January 2015; revised 20 May 2015; accepted 26 May 20I5; accepted article preview online 8 June 2015 the polymorphic region or 5-HTTLPR), which gives rise to long (l) and short (s) alleles. Specifically, many (but not all) studies associate a low 5-HTT-expressing polymorphism $(\mathrm{s} / \mathrm{s})$ with greater risk for anxiety-related traits (Lesch et al, 1996) and posttraumatic stress disorder (Lee et al, 2005), whereas a high 5-HTT-expressing variation (1/l) associates with reduced anxiety and depression susceptibility (Lesch et al, 1996), especially when combined with environmental factors (Caspi et al, 2003; Uher and McGuffin, 2010).

Importantly, variations of the 5-HTT gene have been associated with altered neural pathways linked to fear: for instance, $1 / 1$ carriers demonstrate reduced activation of the amygdala in response to fearful faces (Hariri et al, 2002), together with altered functional connectivity between amygdala and medial prefrontal cortex (mPFC) (Canli et al, 2005; Pezawas et al, 2005), although not all studies are consistent with these findings (Murphy et al, 2013).

While human 5-HTT gene association studies are complicated by multiple environmental and demographic factors, transgenic mouse models allow for a more controlled analysis of the impact of 5-HTT gene variation on behavior and neural function. The 5-HTT knockout (5-HTTKO) mice display increased trait anxiety (Holmes et al, 2003) and impaired fear extinction recall (Wellman et al, 2007), whereas the 5-HTT-overexpressing (5-HTTOE) mice are characterized by a low anxiety phenotype (Jennings et al, 2006) and impaired fear memory (Barkus et al, 2014; Line 
et al, 2014). Anatomical and electrophysiological evidence has confirmed that differential 5-HTT expression can alter structure and function of the amygdala, a brain region encoding fear. More specifically, 5-HTTKO mice display altered synchrony between the basolateral amygdala (BLA) and the mPFC (Narayanan et al, 2011), as well as abnormal dendritic spine density in principal neurons (PNs) of the BLA (Wellman et al, 2007). Recently, recordings from the BLA of 5-HTTOE mice revealed attenuated fear-evoked theta oscillations (Barkus et al, 2014). Collectively, these studies suggest that alterations in 5-HTT gene expression impact on the microcircuitry of the BLA; however, the mechanisms are unknown.

Timed inhibition from GABAergic interneurons (INs), in particular parvalbumin-expressing INs (PVINs), to PNs is thought to be involved in the control of theta oscillations (Courtin et al, 2014; Klausberger et al, 2003). 5-HT released from axons originating from cell bodies in the midbrain is believed to modulate BLA activity primarily through the recruitment of local INs (Rainnie, 1999). Importantly, midbrain 5-HT neurons can fire phase locking to theta oscillations (Kocsis and Vertes, 1992) and modulate limbic theta rhythms (Jackson et al, 2008). Taken together, these data suggest that the evidence for reduced theta power in response to aversive cues in the BLA of 5-HTTOE mice could be a sign of dysfunctional inhibitory inputs from GABAergic INs to PNs.

To test this hypothesis, we investigated the activity of PVINs, a GABAergic population accounting for more than $40 \%$ of all the INs in the rodent basal amygdala (BA) (McDonald and Mascagni, 2001). In particular, we examined whether BA PVINs of 5-HTTOE mice would display differential recruitment during fear memory retrieval combined with altered sensitivity to 5-HT.

\section{MATERIALS AND METHODS}

\section{Subjects}

We used female 5-HTTOE mice and littermate wild-type (WT) controls (C57BL/6 $\times$ CBA background, 4-6 months age for electrophysiology, 4-11 months age for behavior). A detailed description of how 5-HTTOE mice were generated can be found in Jennings et al., 2006. Mice were housed 2-6 per cage on a $12 \mathrm{~h}$ light/dark cycle and at a temperature of $19-22^{\circ} \mathrm{C}$ with free access to food and water. Testing took place during the light cycle. Mice were handled in the 2 days before fear conditioning began. The experiments were conducted in accordance with the United Kingdom Animals Scientific Procedures Act (1986) under project licenses PPL 30/3061 and 30/3068 and were approved by local ethical review at the University of Oxford.

\section{Fear Conditioning}

Mice received five training trials (paired group: $30 \mathrm{~s}$ tone followed by $0.3 \mathrm{~mA}, 0.5 \mathrm{~s}$ shock; unpaired group: tone and shock never paired together; tone-alone group: $30 \mathrm{~s}$ tone only) in one context followed $24 \mathrm{~h}$ later by one tone-alone presentation in a novel context. Mice were then individually housed in a darkened room for $2 \mathrm{~h}$, after which they were perfused transcardially with $0.1 \mathrm{M}$ phosphate-buffered saline (PBS, pH 7.3) followed by a fixative solution containing
$4 \%$ paraformaldehyde (PFA) and $15 \%(\mathrm{v} / \mathrm{v})$ saturated picric acid in $0.1 \mathrm{M}$ phosphate buffer ( $\mathrm{PB}$; $\mathrm{pH} 7.3)$. Brains were extracted, postfixed overnight at $4{ }^{\circ} \mathrm{C}$ in the same fixative solution, and processed as described in the Immunohistochemistry section. For a detailed description of the fear conditioning paradigm and apparatus see Supplementary Materials and Methods.

\section{Fear Conditioning Data Analysis}

Freezing behavior was measured using a script in NIH Image (Barkus et al, 2014), which analyzed consecutive video frames ( $1 \mathrm{~Hz}$ sampling) for pixel changes and assigned a freezing score if the \% pixel change was below a set threshold calibrated for an absence of movement except for breathing. This automated system has over $80 \%$ concordance with experimenter ratings of freezing behavior and gives an unbiased measure of immobility, as described elsewhere (Richmond et al., 1998). We calculated a freezing difference score by subtracting freezing during the preconditioned stimulus (CS) period from freezing during CS presentation. Positive freezing difference scores therefore indicate increased freezing compared with the pre-CS period, whereas negative difference scores indicate decreased freezing compared with the pre-CS period.

\section{Acute Slice Preparation}

Naïve WT and 5-HTTOE mice were decapitated under deep isoflurane anesthesia $\left(4 \%\right.$ in $\left.\mathrm{O}_{2}\right)$. The brains were rapidly removed and immersed in ice-cold oxygenated cutting solution with the following composition (in $\mathrm{mM}$ ): $0.5 \mathrm{CaCl}_{2}$, 10 glucose, $2.5 \mathrm{KCl}, 7 \mathrm{MgCl}_{2}, 85 \mathrm{NaCl}, 25 \mathrm{NaHCO}_{3}, 1.25$ $\mathrm{NaH}_{2} \mathrm{PO}_{4}$, and 65 sucrose (all from Sigma-Aldrich) saturated with $95 \% \mathrm{O}_{2}$ and $5 \% \mathrm{CO}_{2}$ at $\mathrm{pH}$ 7.3. Coronal slices of $325 \mu \mathrm{m}$ thickness including the BLA ( -1.4 to $-2 \mathrm{~mm}$ from bregma) were sliced at $4{ }^{\circ} \mathrm{C}$ using a microtome (Microm HM 650V; Thermo Fisher), and then incubated at $36^{\circ} \mathrm{C}$ for $30 \mathrm{~min}$. During the incubation period, the cutting solution was substituted at a rate of $\sim 5 \mathrm{ml} / \mathrm{min}$ with oxygenated artificial cerebrospinal fluid (ACSF) composed of (in $\mathrm{mM}$ ): $2.5 \mathrm{CaCl}_{2}$, 10 glucose, $3.5 \mathrm{KCl}, 1.5 \mathrm{MgSO}_{4}, 130 \mathrm{NaCl}, 24 \mathrm{NaHCO}_{3}$, and $1.25 \mathrm{NaH}_{2} \mathrm{PO}_{4}$ saturated with $95 \% \mathrm{O}_{2}$ and $5 \% \mathrm{CO}_{2}$ at $\mathrm{pH} 7.3$.

\section{Electrophysiology}

Slices were transferred to a submerged recording chamber and continuously perfused with oxygenated ACSF at a rate of $\sim 5 \mathrm{ml} / \mathrm{min}$ at $34 \pm 1{ }^{\circ} \mathrm{C}$. Neurons were visualized with an upright Axioskop microscope (Zeiss) using phase-contrast microscopy under a LUMPlanFI $60 \times$ immersion objective (Olympus). Micropipettes (5-6 M $\Omega$ ) were pulled from borosilicate glass capillaries (GC120F, $1.2 \mathrm{~mm}$ o.d.; Clarke Electromedical Instruments) with a DMZ puller (Zeitzinstrumente $\mathrm{GmbH}$ ). Somatic whole-cell patch-clamp recordings were performed from visually identified neurons in the BA, characterized by higher number of PVINs (McDonald and Mascagni, 2001) and dense serotonergic innervation (Asan et al, 2013). Electrodes were filled with an intracellular solution composed of (in $\mathrm{mM}$ ): 126 K-gluconate, $4 \mathrm{KCl}, 4$ ATP-Mg, 0.3 GTP-Na, 10 $\mathrm{Na}_{2}$-phosphocreatine, $10 \mathrm{HEPES}$, and $0.5 \%(\mathrm{w} / \mathrm{v})$ biocytin 
(all from Sigma-Aldrich). Electrophysiological signals were amplified using an EPC9/2 amplifier (HEKA Electronik) and acquired using Patchmaster software (HEKA Electronik). Recordings were accepted only when the initial seal resistance was $>2 \mathrm{G} \Omega$ and the series resistance did not change $>20 \%$ throughout the experiment. PNs were distinguished from INs by their larger somata $(\geqslant 20 \mu \mathrm{m}$ diameter), lower ( $\leqslant 200 \mathrm{M} \Omega) \mathrm{R}_{\mathrm{in}}$, adapting firing patterns in response to prolonged current injections, broad spikes ( $\sim 1 \mathrm{~ms}$ half-width), and higher membrane time constant $(\tau)$, in line with previous reports (Sosulina et al, 2006). For inhibitory postsynaptic currents (IPSCs) and sinusoidal current injections recording see Supplementary Materials and Methods. The experimenters were blind to genotypes. At the end of the recording, slices were fixed overnight at $4{ }^{\circ} \mathrm{C}$ in $4 \%$ PFA and $15 \%$ saturated picric acid in $0.1 \mathrm{M} \mathrm{PB}$. After $24 \mathrm{~h}$, slices were embedded in gelatin and resectioned into $60 \mu \mathrm{m}$ sections with a VT-1000 vibrating microtome (Leica).

\section{Electrophysiological Data Analysis}

Analysis of synaptic currents and intrinsic membrane properties were performed using IGOR Pro 6 (Wavemetrics). IPSCs were detected using TaroTools toolbox for Igor Pro (https://sites.google.com/site/tarotoolsregister/). Electrophysiological parameters of single neurons were analyzed as described previously (Manko et al, 2012). For a detailed description see Supplementary Materials and Methods.

\section{Immunohistochemistry}

Brains from fear-conditioned animals were cut into $60-\mu \mathrm{m}$ thick coronal sections. Sections were stained with the following primary antibodies: guinea-pig anti-PV $(1: 2000$; Synaptic Systems) and rabbit anti-c-Fos antibodies (1:500; Abcam).

Recorded INs were stained with Cy3- (Life Technologies) or Alexa 488-conjugated (Invitrogen) streptavidin (1:10003000). Somatic immunoreactivity was assessed using guineapig anti-PV (1:2000; Synaptic Systems) or goat anti-PV (1:500; Abcam) primary antibodies. Immunoreactivity of the recorded neurons was visualized using an epifluorescence microscope (AxioImager M2; Zeiss) or a laser-scanning confocal microscope (LSM 710; Zeiss). For a detailed description of immunohistochemical procedures see Supplementary Materials and Methods.

\section{Quantification of c-Fos- and PV-Positive Neurons}

Sections containing the BA from fear-conditioned mice were scanned using an epifluorescence microscope (AxioImager M2; Zeiss) under a $40 \times$ objective. Counting of c-Fos- and PV-positive neurons was performed in StereoInvestigator (MBF Bioscience). The experimenter was blind to genotypes and behavioral testing conditions. For a detailed description of the quantification method see Supplementary Materials and Methods.

\section{Statistical Analysis}

Data are presented as means \pm SEM values. Distributions passing the Shapiro-Wilk test for normality were compared using Student's $t$-tests and ANOVAs with Bonferroni multiple comparisons correction. Non-normal distributions were compared using Mann-Whitney test and KruskallWallis test with Dunn's multiple comparisons correction. Cumulative distributions of inter-IPSCs intervals were compared using Kolmogorov-Smirnov test. Statistical analysis was performed with SPSS (IBM) and $P<0.05$ was considered statistically significant.

\section{Drugs}

Serotonin hydrochloride, MDL 72 222, RS 102221, MDL 100 907, SR95531, and CGP 54626 hydrochloride were purchased from Tocris Bioscience UK. Picrotoxin, kynurenic acid, and $\alpha$-methylserotonin maleate salt were purchased from Sigma-Aldrich UK.

\section{RESULTS}

\section{5-HTT Overexpression Leads to Impaired PVIN Activation by Fear Memory}

In the BLA, PVINs are excited by the CS during fear conditioning (Wolff et al, 2014). Moreover, as PVINs are strongly involved in the generation of local theta oscillations, we postulated that abnormal CS-evoked theta activity in 5-HTTOE mice (Barkus et al, 2014) might reflect reduced recruitment of PVINs.

To test this hypothesis, we subjected 5-HTTOE and littermate WT mice to an auditory fear conditioning paradigm (Figure 1a). During the fear memory test session, the onset of the tone CS evoked a large increase in freezing in mice in the paired condition, with a slight increase in freezing in mice in the unpaired condition, and either no increase (WT) or a slight decrease in freezing (5-HTTOE) in mice in the tone-alone condition (Figure 1a and Supplementary Figure S1). Statistical analysis confirmed these observations. Mice in the paired condition showed a significantly larger increase in freezing with cue onset compared with mice in the tone-alone and unpaired conditions (phase (pretone vs tone) $\times$ training condition interaction: $F(1,38)=20.4 ; P<0.001)$. These differences were present only during tone presentation (paired $v s$ unpaired: $P<0.05$; paired $v s$ tone-alone: $P<0.001$ ), with no differences in freezing during the pretone periods (all $P>0.5$ ). Although the three-way interaction between genotype, training condition, and phase did not reach significance $(\mathrm{F}(2,50)=2.0, P>0.05)$, we performed separate ANOVAs (with factors of genotype and phase) for each training condition. In the paired condition, there was a genotype $x$ phase interaction $(\mathrm{F}(1,24)=7.2, P<0.05)$ reflecting the larger increase in freezing from the pre-CS to CS period in WT compared with 5-HTTOE mice. Performing a $t$-test on the freezing 'difference score' (CS freezing - pre-CS freezing) confirmed that the change in freezing evoked by the CS was greater in WTs compared with that in 5-HTTOEs $(t(24)=2.7, P<0.05$; Figure 1a). For the ANOVAs performed on the unpaired and tone-alone condition, there was no effect of genotype or interaction between phase and genotype, with WTs and 5-HTTOEs showing similar responses in these training conditions (Figure 1a). Thus, in the paired condition, cue-evoked freezing was lower in 
5-HTTOE mice, consistent with previous reports (Barkus et al, 2014; Line et al, 2014).

Two hours after the fear memory test session, mice were perfused and sections containing the BA were immunostained for both c-Fos, a marker of neuronal activation, and PV to probe the activation of PVINs during fear memory retrieval. Somatic c-Fos immunoreactivity was detected in the BA of both WT and 5-HTTOE mice
(Figure 1b). We observed a significant effect of condition in the amount of c-Fos-expressing (c-Fos+) neurons $(\mathrm{F}(2,24)=5.4, P<0.05)$. Mice in the paired condition displayed a greater number of c-Fos+ cells compared with mice in the unpaired and tone-alone conditions (both $P<0.05$; Figure 1d). These results suggest that fear memory retrieval reliably recruited neurons in the BLA in both WT and 5-HTTOE mice.
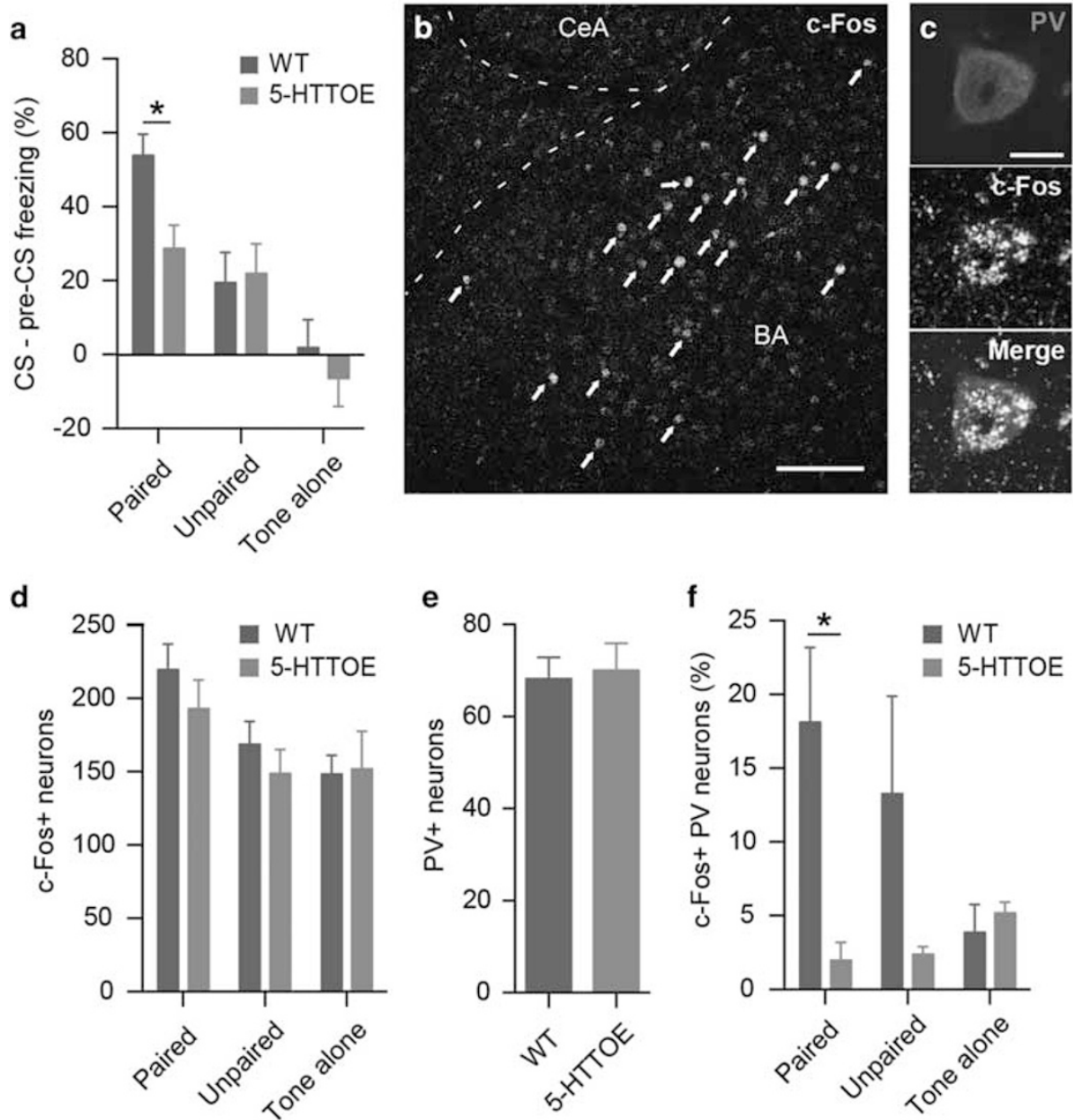

Figure I Increased 5-hydroxytryptamine transporter (5-HTT) expression leads to reduced fear recruitment of parvalbumin-expressing interneurons (PVINs) in the basal amygdala (BA). (a) Reduced freezing responses in 5-HTT-overexpressing (5-HTTOE) mice in the conditioned stimulus-unconditioned stimulus (CS-US) paired condition during fear testing session (paired: wild type (WT), $n=14,5$-HTTOE, $n=12$; unpaired: WT, $n=7,5$-HTTOE, $n=7$; tone alone: WT, $n=8,5-\mathrm{HTTOE}, n=8$ ). (b) Representative c-Fos expression in the BA following the fear testing session. Arrows indicate c-Fos+ neurons. Scale bar: $100 \mu \mathrm{m}$. (c) Immunoreactivity of a representative neuron for PV and c-Fos. Scale bar: $10 \mu \mathrm{m}$. (d) Overall numbers of c-Fos+ neurons in the basolateral amygdala (BLA) do not differ between WT and 5-HTTOE mice following the fear testing session ( $n=5$ per genotype and condition). (e) Overall numbers of $\mathrm{PV}+$ neurons in the BA do not differ between WT and 5-HTTOE mice following the fear testing session ( $n=5$ per genotype). (f) Reduced numbers of c-Fos $+/ P V+$ in the BA of 5-HTTOE in the paired condition. No significant difference between WT and 5-HTTOE in the unpaired and tone-alone condition ( $n=5$ per genotype and condition). $* P<0.05$. The color reproduction of this figure is available on the Neuropsychopharmacology journal online.

Figure 2 5-Hydroxytryptamine (5-HT)-evoked depolarization of parvalbumin-expressing interneurons (PVINs) of the basolateral amygdala (BLA) is impaired in 5-hydroxytryptamine transporter-overexpressing (5-HTTOE) mice. (a) Recording configuration and schematic connectivity between PVINs and principal neurons (PNs). (b) Representative PVIN filled with neurobiotin during recording. Scale bar: $50 \mu m$. (c) Representative immunoreactivity for PV of a biocytin-filled neuron (same neuron as in b) (d) Five superimposed voltage responses to depolarizing current injections of representative PVINs from a WT (I 60 pA, 300 ms, left) and 5-HTTOE mouse (I 20 pA, 300 ms, right) during control, bath application of 5-HT (50 $\mu$ M), and washout. In control, the current intensities used were set just below threshold to evoke an action potential. (e) Time course of the effect of 5-HT on the membrane potential of WT and $5-H T T O E$ PVINs. (f) 5-HTTOE PVINs ( $n=5$ from five animals) are significantly less depolarized by 5-HT compared with WT PVINs ( $n=7$ from six animals). (g) Time course of the effect of 5-HT on the input resistance of WT and 5-HTTOE PVINs. (h) 5-HT causes a significantly weaker increase in input resistance in 5 -HTTOE compared with WT PVINs. $* P<0.05$. The color reproduction of this figure is available on the Neuropsychopharmacology journal online. 
Although WT and 5-HTTOE mice displayed similar numbers of c-Fos+ cells (main effect of genotype $\mathrm{F}(1,24)=$ $0.9, P>0.1$; Figure 1d), c-Fos $+/ \mathrm{PV}+$ colabeled cells (Figure 1c) were far more numerous in WT mice compared with 5-HTTOE mice following fear memory recall (Figure 1f; main effect of genotype: $\mathrm{F}(1,24)=8.8, P<0.01)$. Post hoc comparisons revealed that WT mice had a greater proportion of c-Fos $+/ \mathrm{PV}+$ cells compared with 5 -HTTOE mice $(P<0.05)$ in the paired condition. We did not observe a significant difference in the unpaired $(P>0.1)$ and tone-alone $(P>0.9)$ conditions, a

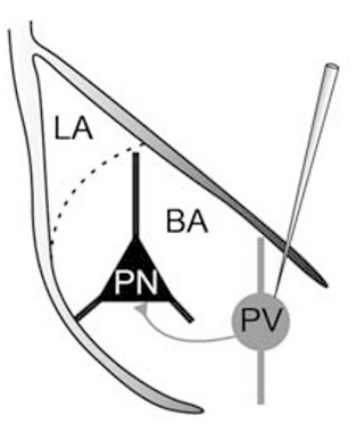

c
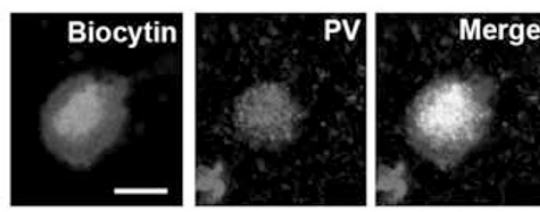

d

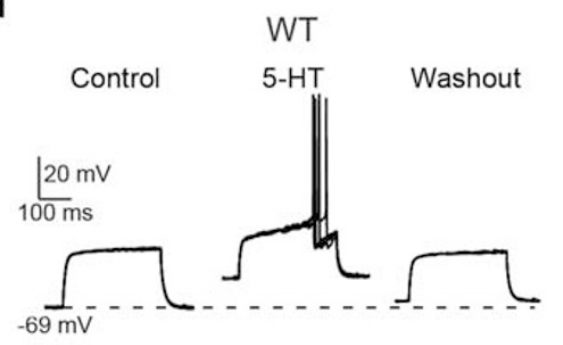

e

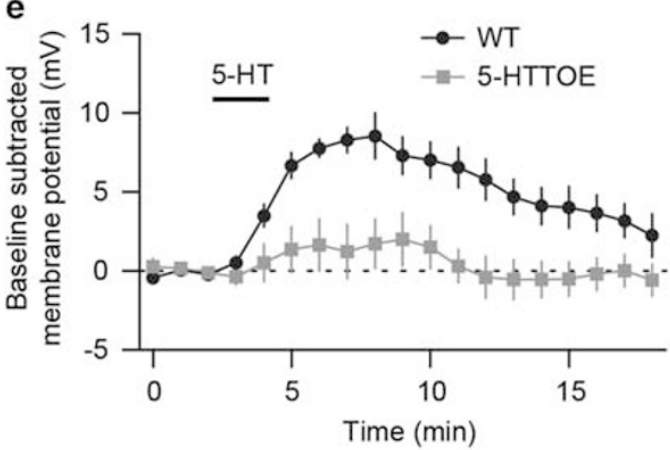

g

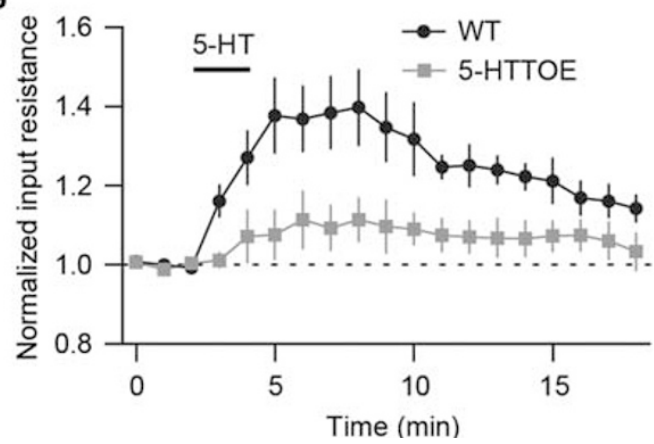

b

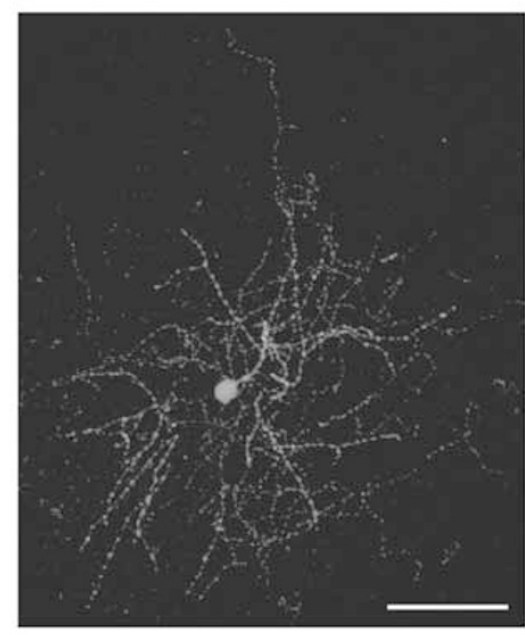

Control

5-HTTOE

5-HT

Washout

$\bigsqcup_{100 \mathrm{~ms}}^{20 \mathrm{~m}}$
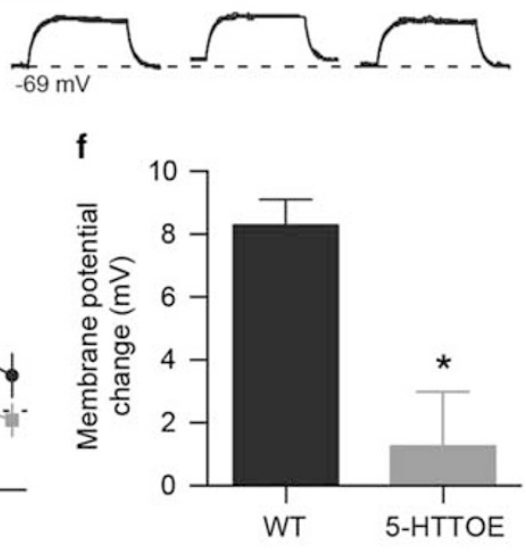

h

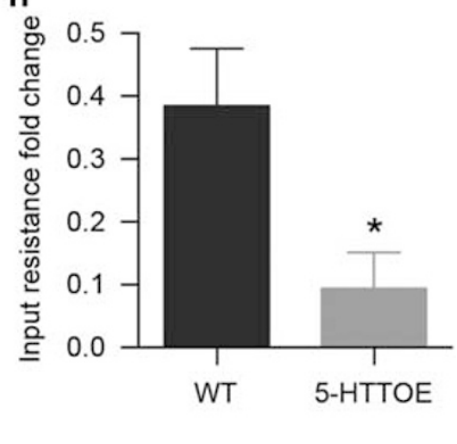


although in the former condition the number of activated PVINs was lower in 5-HTTOE mice. This difference was not driven by a significantly reduced number of c-Fos+ (Figure 1d) or PV+ cells (Figure 1e) in 5-HTTOE mice, arguing that 5-HTTOE mice displayed a cell-type, behavior-specific deficit in the activation of PVINs of the BA evoked by fear.

\section{5-HTT Overexpression Leads to Impaired 5-HT Excitation of PVIN}

Next, we asked whether reduced fear activation of PVINs in the BA of 5-HTTOE mice was accompanied by alterations at the physiological level. As 5-HTT manipulations result in altered synaptic 5-HT levels, and fear conditioning causes release of 5-HT in the BLA (Zanoveli et al, 2009), we investigated the 5-HT sensitivity of PVINs in 5-HTTOE and WT mice. Acute coronal brain slices were prepared and INs were recorded in the BA in whole-cell mode (Figure 2a). Neurons were filled with biocytin (Figure 2b) to allow post hoc immunohistochemical identification of PVINs (Figure 2c). Importantly, we found no significant difference in membrane properties of PVINs between WT and 5-HTTOE mice (Supplementary Table S1).

All PVINs recorded from the BA of WT mice depolarized in response to bath application of 5 -HT $(50 \mu \mathrm{M}, n=7$ from six animals; Figures $2 \mathrm{~d}-\mathrm{f}$ ) and displayed an increase in the input resistance (Figure $2 \mathrm{~g}$ and $\mathrm{h}$ ). Depolarization and change in input resistance were blocked by the $5-\mathrm{HT}_{2 \mathrm{~A}}$ receptor-selective antagonist MDL 100907 (150 nM, $P<0.05, n=5$ from four animals; Supplementary Figure S2), consistent with previous studies reporting the localization of $5-\mathrm{HT}_{2 \mathrm{~A}}$ receptors on this IN type (Jiang et al, 2009; McDonald and Mascagni, 2007). These effects were caused by a direct effect of 5-HT on PVINs because they were also detected in the presence of synaptic blockers (3 mM kynurenic acid, $10 \mu \mathrm{M}$ SR95531, and $5 \mu \mathrm{M}$ CGP 54626; Supplementary Figure S2). In contrast, BA PVINs of 5-HTTOE mice ( $n=5$ from five animals) displayed significantly reduced depolarization and a reduced change in input resistance in response to 5-HT compared with PVINs of WT mice $(P<0.05$ for both parameters; Figure $2 \mathrm{~d}-\mathrm{h})$. These results suggest a link between the impaired recruitment of PVINs of the BA in 5-HTTOE mice during fear and a specific deficit in sensitivity to 5 -HT in the same neuron type.

\section{5-HTT Overexpression Causes Reduced 5-HT-Evoked Inhibitory Drive onto PNs}

As PVINs form the major IN population in the BLA and are the source of a significant inhibitory input to PNs (Woodruff and Sah, 2007), we postulated that reduced 5-HT excitation of PVINs could impact on the 5-HT-mediated inhibition of PNs. To test this, we performed whole-cell patch-clamp recordings from PNs of the BA of both WT and 5-HTTOE mice (Figure $3 \mathrm{a}$ and $\mathrm{b}$ ). PNs were identified according to defined electrophysiological parameters (see Materials and methods and Supplementary Table S2), including stereotypic firing (Figure 3c). Importantly, passive membrane properties of PNs were not influenced by genotype (Supplementary Table S1).

We recorded spontaneous IPSCs (sIPSCs), a read-out of the activity of local GABAergic INs (sIPSC basal frequency in WT: $0.42 \pm 0.13 \mathrm{~Hz}$; in 5-HTTOE: $0.25 \pm 0.12 \mathrm{~Hz}, P>0.1$, $n=9$ each). These currents were blocked by application of the $\mathrm{GABA}_{\mathrm{A}}$ antagonist picrotoxin $(100 \mu \mathrm{M}, n=3$, data not shown), confirming the GABAergic nature of these inputs. Consistent with previous reports (Jiang et al, 2009; Rainnie, 1999), 5-HT $(50 \mu \mathrm{M})$ markedly enhanced the frequency of sIPSCs in all PNs recorded from WT mice $(n=9$ from seven animals, Figure $3 \mathrm{~d}$ and e). In agreement with earlier observations (Jiang et al, 2009), this effect of 5-HT appeared to be mediated primarily through $5-\mathrm{HT}_{2 \mathrm{~A}}$ receptors, as the selective antagonist MDL 100907 (150 nM, $n=5$ from four animals) significantly reduced the facilitation of sIPSCs by 5 -HT (increase in sIPSCs frequency in WT vs WT+MDL 100 907, $P<0.05$; Supplementary Figure S3). Additional blockade of $5-\mathrm{HT}_{2 \mathrm{C}}$ and $5-\mathrm{HT}_{3}$ receptors (using $1 \mu \mathrm{M}$ RS 102221 and $20 \mu \mathrm{M}$ MDL 72222 , respectively, $n=4$ from four animals) completely prevented the increase in sIPSC frequency induced by 5 -HT $(P<0.01$ vs WT; Supplementary Figure S3), consistent with evidence for the presence of these receptors on non-PV IN types in the BLA (Bonn and Schmitt, 2013; Mascagni and McDonald, 2007).

In 5-HTTOE mice ( $n=9$ from eight animals), 5-HT produced a smaller increase in the frequency of sIPSCs compared with WT mice $(P<0.001$; Figure $3 \mathrm{f}-\mathrm{i})$. Overall, these data suggest that the 5 -HT facilitation of GABA release onto PNs of the BA is impaired in 5-HTTOE mice, leading to reduced membrane hyperpolarization in PNs (5-HT-evoked PNs hyperpolarization WT vs 5-HTTOE, $P<0.05$; WT: $n=8$; 5-HTTOE: $n=10$; Supplementary Figure S4). In contrast, direct hyperpolarization of PNs appeared unaffected by 5-HTT overexpression (WT vs 5-HTTOE, $P<0.05$; WT: $n=9$; 5-HTTOE: $n=7$; Supplementary Figure S4C and D). Notably, preincubation of the slices with the selective serotonin reuptake inhibitor (SSRI) citalopram $(1 \mu \mathrm{M}, n=8$ from four animals) ameliorated, but did not completely rescue, the deficit in 5-HT-evoked sIPSCs observed in PNs recorded in 5-HTTOE mice (increase in sIPSCs frequency in

\footnotetext{
Figure 3 Indirect inhibition of principal cells by 5-hydroxytryptamine (5-HT) is impaired in 5-hydroxytryptamine transporter-overexpressing (5-HTTOE) mice. (a) Recording configuration and schematic connectivity between parvalbumin-expressing interneurons (PVINs) and principal neurons (PNs) (b) Representative PN filled with neurobiotin during recording. Scale bar: $100 \mu \mathrm{m}$. (c) Adapting firing pattern of the neuron shown in (b) in response to prolonged (I s) current injection (300 pA). (d) Representative voltage clamp (-50 mV) trace from a WT PNs during control, 5-HT (50 $\mu$ M) application, and washout. (e)

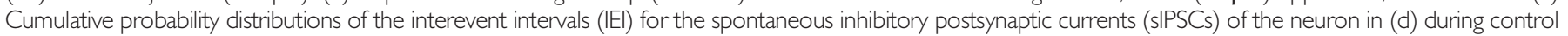

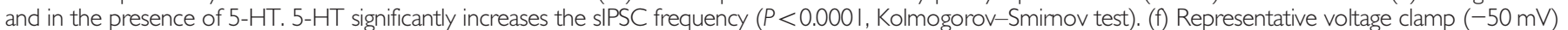

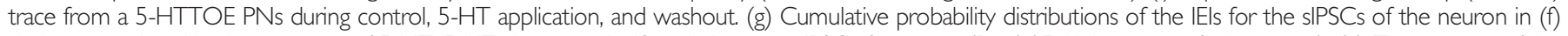

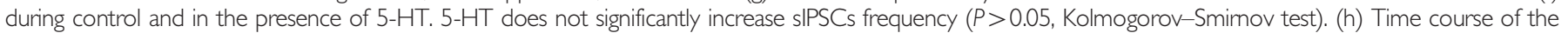

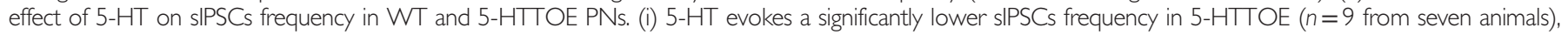

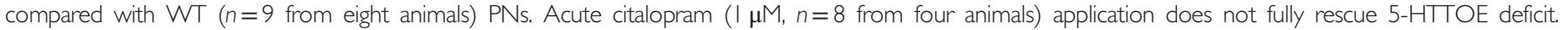
*** $P<0.001 ; * P<0.05$. The color reproduction of this figure is available on the Neuropsychopharmacology joumal online.
} 
5-HTTOE vs 5-HTTOE+citalopram, $P>0.05$; Figure $3 \mathrm{~h}$ and i). These data suggest that 5-HTTOE mice display a deficit in 5-HT-induced inhibition of PNs of the BA by
GABAergic INs. This deficit is likely to be mediated, at least in part, by impaired 5-HT-mediated depolarization of PVINs. This loss of sensitivity to $5-\mathrm{HT}$ in the 5 -HTTOE

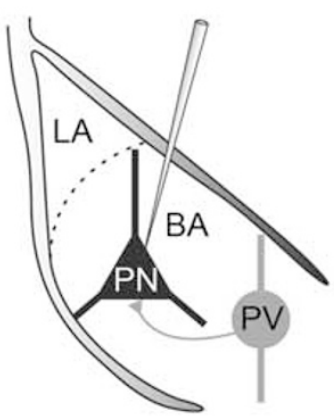

C

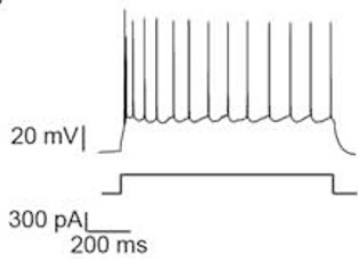

d

WT

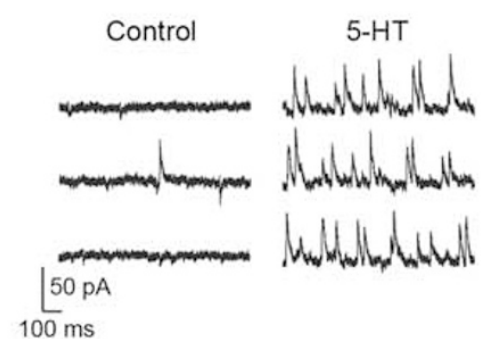

f

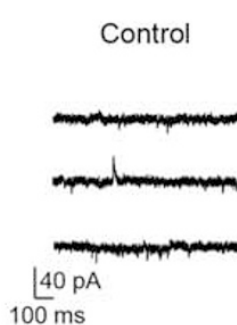

h

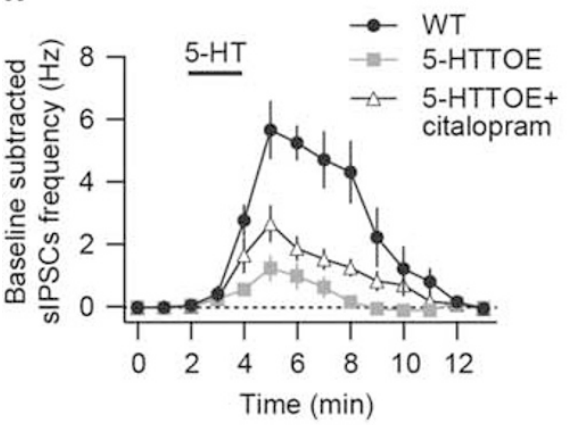

b

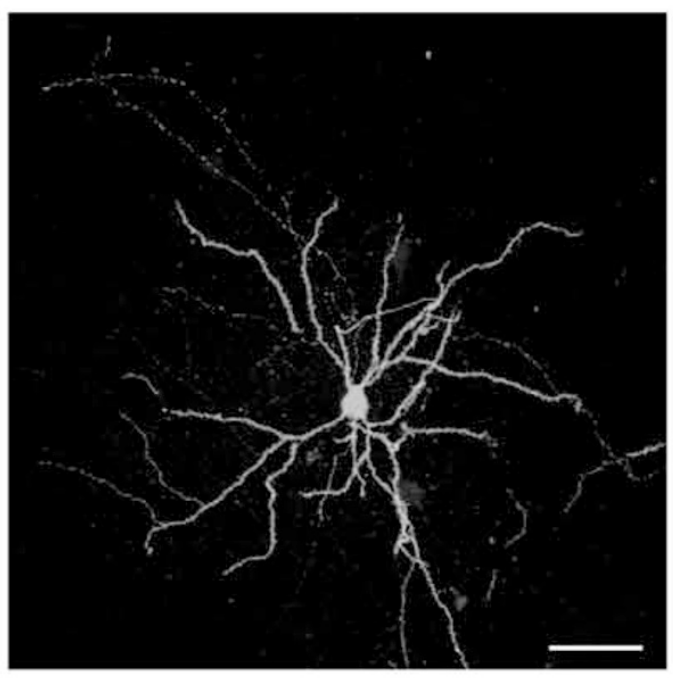

e

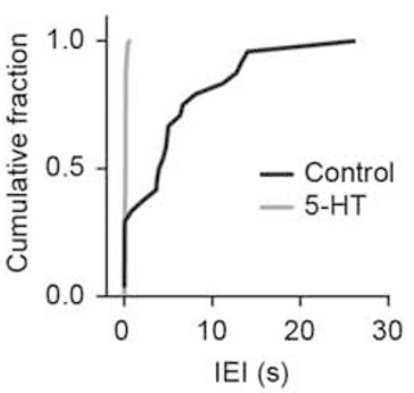

g

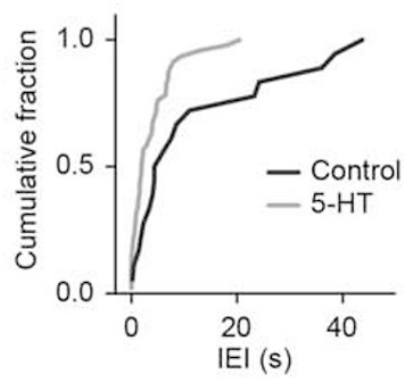

i

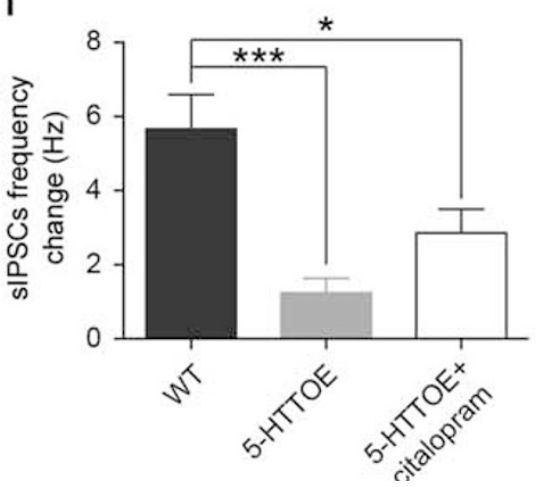


mice is not entirely explained by an ongoing increase in the reuptake of 5-HT, as it could not be completely rescued by pharmacological blockade of the 5-HTT.

\section{Impaired 5- $\mathrm{HT}_{2 \mathrm{~A}}$ Function Underlies Deficit in 5-HT-Evoked Inhibition of PNs}

We reasoned that the reduced 5-HT-evoked excitation of PVINs observed in the 5-HTTOE mice could be caused by a loss of function at the level of $5-\mathrm{HT}_{2 \mathrm{~A}}$ receptors. Crucially, the $5-\mathrm{HT}_{2 \mathrm{~A}}$ receptor is the main mediator of the excitatory effect of 5-HT on BLA INs, and this receptor is located primarily on PVINs (Jiang et al, 2009; McDonald and Mascagni, 2007). Thus, we asked whether reduced $5-\mathrm{HT}_{2 \mathrm{~A}}$ receptor function could account for impaired 5-HT-induced excitation of PVINs in 5-HTTOE mice.

The $5-\mathrm{HT}_{2 \mathrm{~A}}$ agonist $\alpha$-methyl-5-HT was applied while recording sIPSCs on PNs (sIPSC basal frequency in WT: $0.04 \pm 0.01 \mathrm{~Hz}$; in 5 -HTTOE: $0.07 \pm 0.01 \mathrm{~Hz}, P>0.1, n=13$ each). In WT mice, bath application of $\alpha$-methyl-5-HT ( $30 \mu \mathrm{M}, n=13$ from four animals) increased the frequency of sIPSCs (Figure $4 \mathrm{a}$ and b). This effect was almost entirely abolished by MDL 100907 ( $150 \mathrm{nM}, n=5$; increase in sIPSCs frequency WT vs WT+MDL $100907, P<0.01$; Figure $4 c, d, g$, and $h$ ), indicating that $\alpha$-methyl-5-HT acts selectively on $5-\mathrm{HT}_{2 \mathrm{~A}}$ receptors to facilitate $\mathrm{GABA}$ release, presumably by depolarization of PVINs (Jiang et al, 2009). In comparison with WT mice, in 5-HTTOE mice application of $\alpha$-methyl-5-HT produced a much smaller increase in the sIPSC frequency in PNs $(P<0.01, n=13$ from three animals; Figure $4 \mathrm{e}-\mathrm{h})$. Taken together, these data demonstrate that, in the BA, increased 5-HTT expression is associated with impaired 5- $\mathrm{HT}_{2 \mathrm{~A}}$ receptor-mediated activation of INs innervating PNs. As PVINs are the main IN type expressing $5-\mathrm{HT}_{2 \mathrm{~A}}$ receptors in the $\mathrm{BA}$, this deficit likely arises from dysfunctional PVINs.

\section{5-HTT Overexpression Causes Deficient 5-HT Modulation of PNs Firing}

Finally, to understand the functional consequences of reduced 5-HT-driven inhibition of PNs, we examined 5 -HT modulation of PN firing in the two genotypes. We injected theta frequency sinusoidal currents that evoked firing in $\sim 50 \%$ of the oscillation peaks. Application of $50 \mu \mathrm{M}$ 5 -HT reliably suppressed the firing of PNs from WT mice ( $n=6$ from three animals; Figure $5 \mathrm{a}$ and $\mathrm{c}$ ). In contrast, the reduction in firing rate evoked by $5-\mathrm{HT}$ was significantly weaker in PNs from 5-HTTOE mice $(P<0.01, n=5$ from two animals, Figure 5b-d). Hence, 5-HTT overexpression causes a differential 5-HT modulation of PNs firing, likely affecting BA excitatory output (Figure $5 \mathrm{e}$ and $\mathrm{f}$ ).

\section{DISCUSSION}

The present study demonstrates two novel findings on how variation in 5-HTT expression impacts upon the microcircuitry of the BA. First, the c-Fos data show that increased 5-HTT expression results in reduced recruitment of BA PVINs during fear. Second, the electrophysiological results demonstrate a selective impairment in 5-HT-evoked excitation of PVINs, leading to reduced inhibition of PNs. Thus, increased 5-HTT expression leads to a loss of 5-HT control over PVINs and therefore over PN firing, likely affecting BA output to the central amygdala and the processing of fear (Figure $5 \mathrm{e}$ and $\mathrm{f}$ ). To our knowledge, these findings provide the first evidence of changes in the function of neurochemically defined neuron types because of genetic alterations in 5-HTT expression.

PVINs of the BLA increase their firing rates in response to CS presentation during fear conditioning (Wolff et al, 2014). Our data are consistent with this finding because presentation of a tone predicting a footshock significantly increased c-Fos expression in BA PVINs in WT mice. PVINs target the perisomatic region of PNs (Bienvenu et al, 2012), inhibiting and synchronizing their firing (Popescu and Paré, 2011; Ryan et al, 2012; Woodruff and Sah, 2007) and disinhibiting their dendrites (Wolff et al, 2014). Hence, they tightly control the BLA output to the central amygdala, orchestrating fear responses. Crucially, inhibiting PVINs during the CS weakens fear learning (Wolff et al, 2014). Thus, reduced freezing responses to the CS observed in 5-HTTOE mice (see also Barkus et al, 2014; Line et al, 2014) could be directly linked with reduced excitation of PVINs during the CS. Although the present study does not demonstrate a causal relationship between reduced PVIN activation and reduced fear in 5-HTTOE mice, a defective encoding of the CS by PVINs could (1) fail to disinhibit PN dendrites, by lack of direct inhibition of somatostatin-expressing neurons, which are also inhibited by PVINs (Wolff et al, 2014); (2) contribute to recently reported weaker theta oscillations (Barkus et al, 2014); and (3) lead to reduced fear (current study; Barkus et al., 2014; Line et al., 2014). Furthermore, we cannot fully resolve whether PVIN activation arises from fear memory recall, sensitization by footshock, or fear generalization to the tone or the testing context. This is because tone-evoked freezing and PVIN activation in WT mice were weak but not absent in the unpaired condition. Future experiments could test whether manipulation of PVINs in the $\mathrm{BA}$ is sufficient to rescue the fear deficits in 5HTTOE mice.

The present study also provides a putative mechanism underpinning the reduced excitation of PVINs of the BA in 5-HTTOE mice, namely reduced sensitivity to 5-HT. This was evident in electrophysiological experiments showing that both 5-HT-evoked depolarization of PVINs associated with the closure of a membrane conductance as well as 5-HTevoked IPSCs in PNs, were reduced in 5-HTTOE compared with WT mice. These deficits are likely caused by reduced functionality of $5-\mathrm{HT}_{2 \mathrm{~A}}$ receptors, as sensitivity to the directacting $5-\mathrm{HT}_{2 \mathrm{~A}}$ receptor agonist, $\alpha$-methyl-5-HT, was also impaired. Reduced 5- $\mathrm{HT}_{2 \mathrm{~A}}$ function could arise from either downregulation or impaired receptor-effector coupling (Béique et al, 2004). Surprisingly, 5-HTT blockade failed to rescue fully the loss of sensitivity to 5 -HT in the 5-HTTOE mice. Therefore, the 5-HT deficit in the BA associated with increased 5-HTT expression appears to be dependent more on $5-\mathrm{HT}_{2 \mathrm{~A}}$ receptor function compared with that on reduced 5 -HT extracellular levels mediated by greater reuptake in 5-HTTOE mice.

The impaired sensitivity of PVINs in 5-HTTOE mice to 5 -HT could be responsible for reduced c-Fos/PV coexpression evoked by fear memory retrieval. This view is appealing because fear activates 5-HT neurons in the midbrain 
a
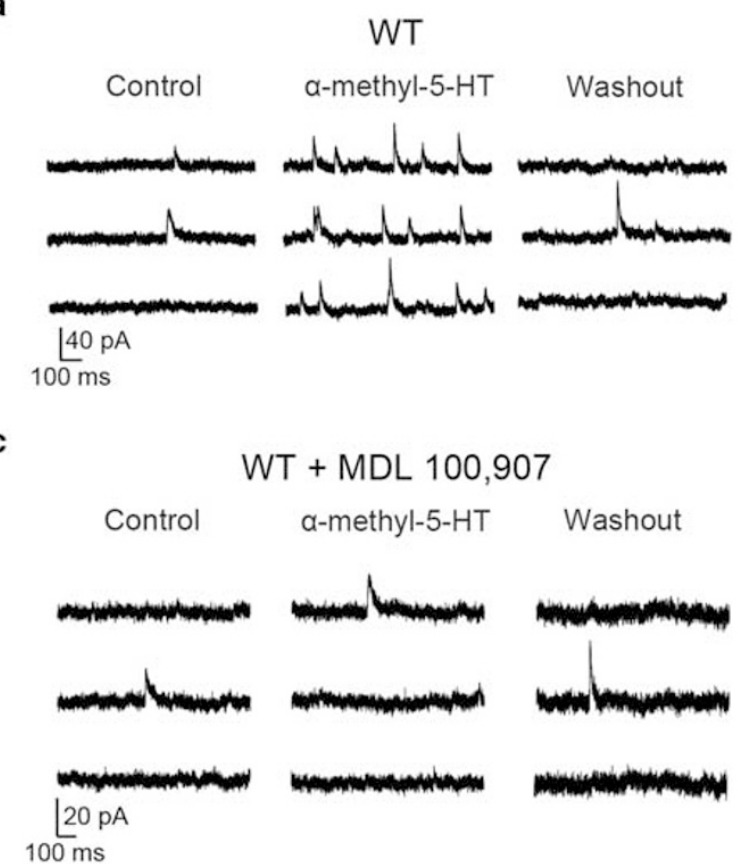

e

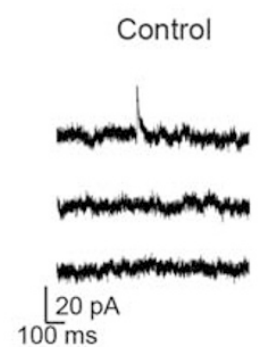

5-HTTOE

a-methyl-5-HT
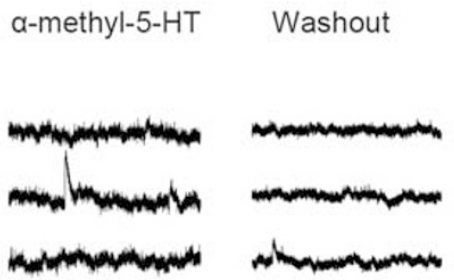

g

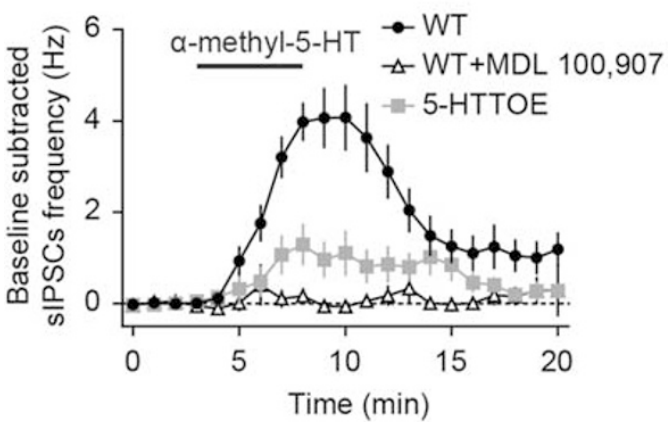

b

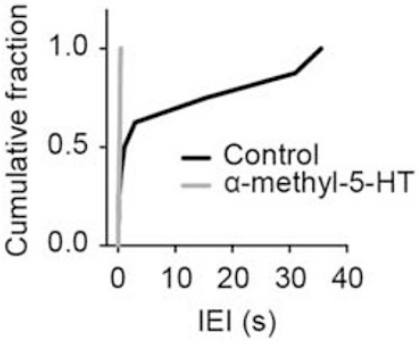

d

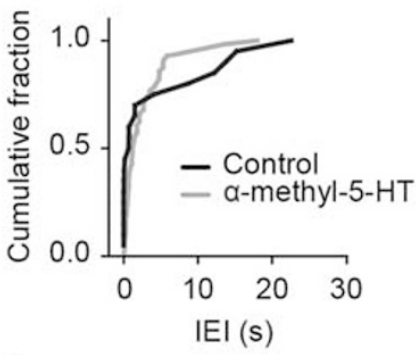

f

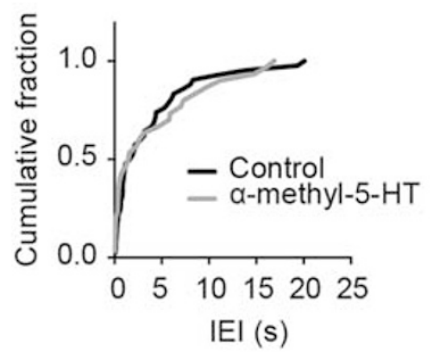

h

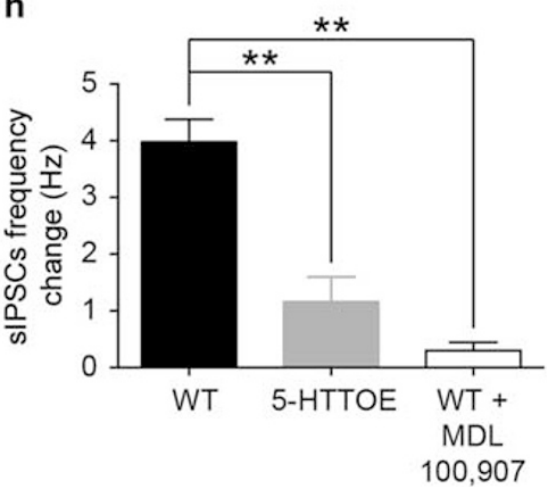

Figure 4 Serotonin $2 \mathrm{~A}\left(5-\mathrm{HT}_{2 \mathrm{~A}}\right)$-mediated inhibition of principal neurons (PNs) is impaired in 5-hydroxytryptamine transporter-overexpressing (5-HTTOE) mice. (a) Representative voltage clamp $(-50 \mathrm{mV}$ ) trace from a wild-type (WT) PNs during control, $\alpha$-methyl-5-HT (30 $\mu$ M) application, and washout. (b) Cumulative probability distributions of the interevent intervals (IEls) for the inhibitory postsynaptic currents (sIPSCs) of the neuron in (d) during control and in the presence of $\alpha$-methyl-5-HT, a 5-HT2 agonist. $\alpha$-Methyl-5-HT significantly increases the sIPSCs frequency $(P<0.000 \mathrm{I}$, Kolmogorov-Smirnov test). (c) Representative voltage-clamp $(-50 \mathrm{mV}$ ) trace from a WT PNs in the presence of the 5-HT $2 \mathrm{~A}$ antagonist MDL 100907 (I50 nM) during control, $\alpha$-methyl-5-HT application, and washout. (d) Cumulative probability distributions of the IEls for the sIPSCs of the neuron in (d) during control and in presence of $\alpha$-methyl-5-HT. This drug does not significantly increase the sIPSCs frequency ( $P>0.05$, Kolmogorov-Smirnov test). (e) Representative voltage-clamp $(-50 \mathrm{mV})$ trace from 5-HTTOE PNs during control, $\alpha$-methyl-5-HT application, and washout. ( $f$ ) Cumulative probability distributions of the IEls for the sIPSCs of the neuron in ( $f$ ) during control and in the presence of $\alpha$-methyl-5-HT. This drug does not significantly increase sIPSC frequency $(P>0.05$, KolmogorovSmirnov test). (g) Time course of the effect of $\alpha$-methyl-5-HT on sIPSCs frequency in WT (with and without 5-HT2A antagonist MDL I00 907) and 5 -HTTOE PNs. (h) $\alpha$-Methyl-5-HT evokes a significantly higher sIPSCs frequency in WT $(n=13$ from four animals) compared with 5 -HTTOE ( $n=13$ from 3 animals) PNs. MDL 100907 blocks the effect of $\alpha$-methyl-5-HT ( $n=5$ from two animals). $* * P<0.0$ I. The color reproduction of this figure is available on the Neuropsychopharmacology journal online. 
a

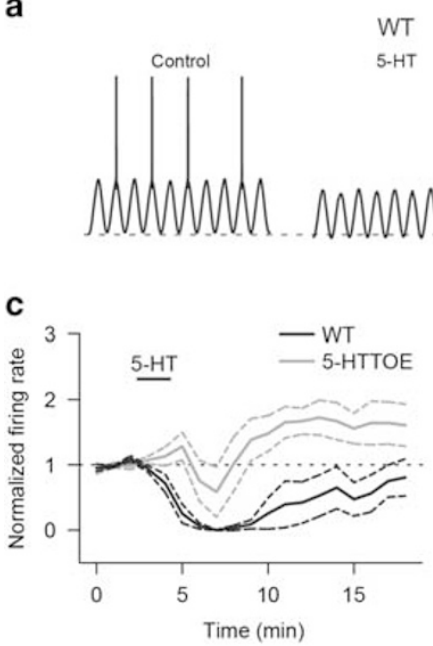

b

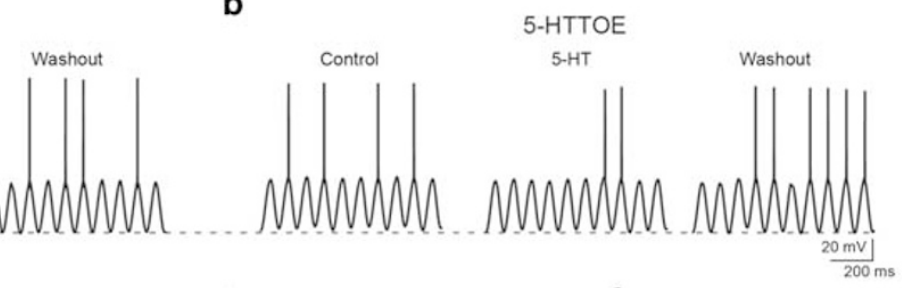

d

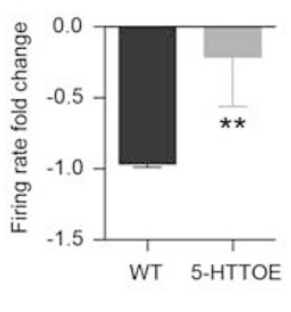

e

Normal 5-HTT expression

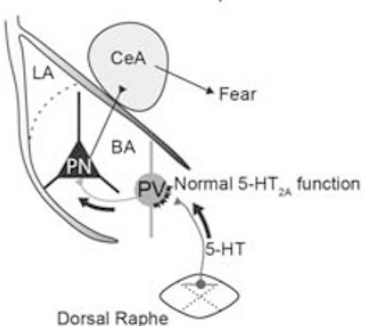

f

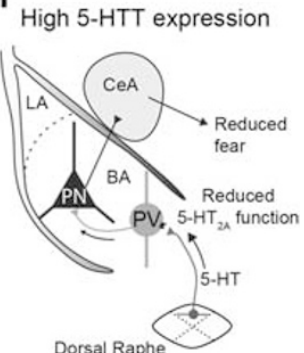

Figure 5 Increased 5-hydroxytryptamine transporter (5-HTT) expression alters the output of basal amygdala (BA) principal neurons (PNs). (a) Sinusoidal current (160 pA intensity) injected at theta frequency $(6 \mathrm{~Hz})$ in a representative wild-type (WT) PN current clamped at - $60 \mathrm{mV}$. Application of 5-hydroxytryptamine (5-HT) $(50 \mu \mathrm{M})$ causes hyperpolarization $(2-3 \mathrm{mV})$ and suppression of firing. (b) Sinusoidal current injection (190 pA) at theta frequency $(6 \mathrm{~Hz})$ in a representative $5-\mathrm{HTT}$-overexpressing $(5-\mathrm{HTTOE}) \mathrm{PN}$ recorded in the current clamp at $-60 \mathrm{mV}$. Application of 5-HT produces a weaker hyperpolarization and fails to suppress firing. (c) Time course of the effect of 5-HT on the firing rate of WT and 5-HTTOE PNs (sinusoidal current injections shown in (a) and (b) delivered every $10 \mathrm{~s}$ ). (d) $5-\mathrm{HT}$ evokes a significantly stronger depression of firing rate in WT ( $n=6$ from three animals) compared with 5-HTTOE ( $n=5$ from two animals) PNs. (e and f) Model of amygdala circuit alterations in 5-HTTOE mice. (e) Dorsal raphe firing, leading to the release of 5-HT in the BA, excites parvalbumin-expressing interneurons (PVINs) through $5-\mathrm{HT}_{2 \mathrm{~A}}$ receptors, leading to indirect perisomatic inhibition of PNs. (f) Increased 5-HTT expression, characterized by lower 5-HT tone because of more efficient 5-HT reuptake, causes reduced 5-HT2A receptor function on PVINs, leading to a failure of dorsal raphe activity to recruit PVINs. This could affect the encoding of sensory stimuli (conditioned stimulus (CS) and unconditioned stimulus (US)) by the PNs, dampening fear responses. ${ }^{*} * P<0.01$. The color reproduction of this figure is available on the Neuropsychopharmacology journal online.

(Spannuth et al, 2011) and triggers the release of 5-HT in the BLA (Zanoveli et al, 2009). Additionally, midbrain 5-HT neurons can fire phase locked to limbic theta oscillations (Kocsis and Vertes, 1992). Thus, their impaired excitation of PVINs in 5-HTTOE mice could contribute to the reduction of theta rhythms in the BLA of these mice (Barkus et al, 2014). This is consistent with the notion that the power of theta rhythm is much more influenced by the interplay between two synaptic current generators, namely dendritic excitation vs PV-perisomatic inhibition of PNs, rather than by PNs spiking per se (Buzsáki, 2002). However, other circuits could also contribute to the weaker activation of PVINs during fear memory retrieval. For instance, 5-HTT overexpression might alter the function of other areas such as the $\mathrm{MPFC}$ and the hippocampus, which are also targeted by 5 -HT fibers and project to the BLA (Hensler, 2006). Unlike PVINs, we did not detect genotypic differences in the overall number of c-Fos+ neurons in the CS-US paired condition, despite PNs receiving impaired inhibition. Although the majority of these activated neurons likely represent PNs, it is important to keep in mind that non-PV IN populations might be included. Furthermore, impaired PVIN output could result in a different temporal distribution of action potentials fired by PNs rather than a long-lasting reduction in their firing rates, with c-Fos protein expression lacking the temporal resolution to reveal such subtle changes.

Our data provide compelling evidence linking increased expression of the 5-HTT with abnormal PVIN function. The 5- $\mathrm{HT}_{2 \mathrm{~A}}$ receptor, which depolarizes PVINs, appears to have a key role in this relationship. Although we cannot fully exclude the possibility that other IN types also contribute to the deficient 5-HT-driven inhibitory inputs to PNs, PVINs are the major GABAergic cell type expressing $5-\mathrm{HT}_{2 \mathrm{~A}}$ receptors in the BLA, in addition to a small number of somatostatin-expressing INs (McDonald and Mascagni, 2007). Adaptive changes in $5-\mathrm{HT}_{2 \mathrm{~A}}$ receptor function because of pharmacological or genetic manipulation of the 5-HTT are consistent with previous studies (Jennings et al, 2008; Li et al, 2003; Marek et al, 2005; Sarkar et al, 2013). Importantly, the direct inhibition by $5-\mathrm{HT}$ of PNs was unaffected in 5-HTTOE mice. This inhibitory effect on BA PNs by 5-HT mirrors the hyperpolarization of cortical pyramidal cells mediated by $5-\mathrm{HT}_{1 \mathrm{~A}}$ receptors (Araneda and Andrade, 1991). Altered 5-HT levels during development because of higher 5-HT reuptake may be responsible for the loss of $5-\mathrm{HT}_{2 \mathrm{~A}}$ function in PVINs. In contrast, $5-\mathrm{HT}_{1 \mathrm{~A}}$ receptors have been shown to develop later in cortical pyramidal cells (Béiqque et al, 2004), thus their later expression on BA PNs might prevent receptor exposure during a sensitive developmental period (Gross et al, 2002). Further experiments examining PVIN function during development are necessary to corroborate this hypothesis.

In summary, our results suggest a novel mechanism through which increased expression of the 5-HTT gene can alter the microcircuitry of the amygdala, namely by changing the function of PVINs. Probing the effects of genetic variation in the 5-HTT or SSRI treatment on neural circuits in limbic areas may open new horizons for understanding the biological basis of emotional behavior. 


\section{FUNDING AND DISCLOSURE}

This work was supported by the Medical Research Council, UK (to MC) (award MC_UU_12020/2) and a Wellcome Trust Senior Fellowship award (to DMB) (Grant No. 087736). Giulia Fucsina was a student of the Master Degree in Neuroscience at the University of Trieste, Italy, and was supported by the Erasmus Placement Exchange. Lydia Oikonomidis was an MSc Neuroscience student at the University of Oxford. The authors declare no conflict of interest.

\section{ACKNOWLEDGMENTS}

We thank K Whitworth, L Norman, J Janson, B Micklem, and L Black for excellent technical support.

\section{REFERENCES}

Araneda R, Andrade R (1991). 5-Hydroxytryptamine2 and 5-hydroxytryptamine $1 \mathrm{~A}$ receptors mediate opposing responses on membrane excitability in rat association cortex. Neuroscience 40: 399-412.

Asan E, Steinke M, Lesch K (2013). Serotonergic innervation of the amygdala: targets, receptors, and implications for stress and anxiety. Histochem Cell Biol 139: 785-813.

Ballenger JC (1999). Current treatments of the anxiety disorders in adults. Biol Psychiatry 46: 1579-1594.

Barkus C, Line SJ, Huber A, Capitao L, Lima J, Jennings $\mathrm{K}$ et al (2014). Variation in serotonin transporter expression modulates fear-evoked hemodynamic responses and theta-frequency neuronal oscillations in the amygdala. Biol Psychiatry 75: 901-908.

Béïque J-C, Campbell B, Perring P, Hamblin MW, Walker P, Mladenovic L et al (2004). Serotonergic regulation of membrane potential in developing rat prefrontal cortex: coordinated expression of 5-hydroxytryptamine (5-HT)1A, 5-HT2A, and 5-HT7 receptors. J Neurosci 24: 4807-4817.

Bienvenu TCM, Busti D, Magill PJ, Ferraguti F, Capogna M (2012). Cell-type-specific recruitment of amygdala interneurons to hippocampal theta rhythm and noxious stimuli in vivo. Neuron 74: 1059-1074.

Blakely RD, De Felice LJ, Hartzell HC (1994). Molecular physiology of norepinephrine and serotonin transporters. J Exp Biol 196: 263-281.

Bonn M, Schmitt A (2013). Serotonergic innervation and serotonin receptor expression of NPY-producing neurons in the rat lateral and basolateral amygdaloid nuclei. Brain Struct 218: 421-435.

Buzsáki G (2002). Theta oscillations in the hippocampus. Neuron 33: 325-340.

Canli T, Omura K, Haas BW, Fallgatter A, Constable RT, Lesch KP (2005). Beyond affect: a role for genetic variation of the serotonin transporter in neural activation during a cognitive attention task. Proc Natl Acad Sci USA 102: 12224-12229.

Caspi A, Sugden K, Moffitt TE, Taylor A, Craig IW, Harrington H et al (2003). Influence of life stress on depression: moderation by a polymorphism in the 5-HTT gene. Science 301: 386-389.

Courtin J, Chaudun F, Rozeske RR, Karalis N, Gonzalez-Campo C, Wurtz H et al (2014). Prefrontal parvalbumin interneurons shape neuronal activity to drive fear expression. Nature 505: 92-96.

Gross C, Zhuang X, Stark K, Ramboz S, Oosting R, Kirby L et al (2002). Serotonin1A receptor acts during development to establish normal anxiety-like behaviour in the adult. Nature 416: 396-400.

Hariri AR, Mattay VS, Tessitore A, Kolachana B, Fera F, Goldman $\mathrm{D}$ et al (2002). Serotonin transporter genetic variation and the response of the human amygdala. Science 297: 400-403.
Hensler JG (2006). Serotonergic modulation of the limbic system. Neurosci Biobehav Rev 30: 203-214.

Holmes A, Lit Q, Murphy DL, Gold E, Crawley JN (2003). Abnormal anxiety-related behavior in serotonin transporter null mutant mice: the influence of genetic background. Genes Brain Behav 2: 365-380.

Hu X-Z, Lipsky RH, Zhu G, Akhtar LA, Taubman J, Greenberg BD et al (2006). Serotonin transporter promoter gain-of-function genotypes are linked to obsessive-compulsive disorder. Am J Hum Genet 78: 815-826.

Jackson J, Dickson CT, Bland BH (2008). Median raphe stimulation disrupts hippocampal theta via rapid inhibition and statedependent phase reset of theta-related neural circuitry. J Neurophysiol 99: 3009-3026.

Jennings KA, Loder MK, Sheward WJ, Pei Q, Deacon RMJ, Benson MA et al (2006). Increased expression of the 5-HT transporter confers a low-anxiety phenotype linked to decreased 5-HT transmission. J Neurosci 26: 8955-8964.

Jennings KA, Sheward WJ, Harmar AJ, Sharp T (2008). Evidence that genetic variation in 5-HT transporter expression is linked to changes in 5-HT2A receptor function. Neuropharmacology 54: 776-783.

Jiang X, Xing G, Yang C, Verma A, Zhang L, Li H (2009). Stress impairs 5-HT2A receptor-mediated serotonergic facilitation of GABA release in juvenile rat basolateral amygdala. Neuropsychopharmacology 34: 410-423.

Klausberger T, Magill PJ, Márton LF, Roberts JDB, Cobden PM, Buzsáki G et al (2003). Brain-state- and cell-type-specific firing of hippocampal interneurons in vivo. Nature 421: 844-848.

Kocsis B, Vertes RP (1992). Dorsal raphe neurons: synchronous discharge with the theta rhythm of the hippocampus in the freely behaving rat. J Neurophysiol 68: 1463-1467.

Lee H-J, Lee M-S, Kang R-H, Kim H, Kim S-D, Kee B-S et al (2005). Influence of the serotonin transporter promoter gene polymorphism on susceptibility to posttraumatic stress disorder. Depress Anxiety 21: 135-139.

Lesch KP, Bengel D, Heils A, Sabol SZ, Greenberg BD, Petri S et al (1996). Association of anxiety-related traits with a polymorphism in the serotonin transporter gene regulatory region. Science 274: $1527-1531$.

Li Q, Wichems CH, Ma L, Van de Kar LD, Garcia F, Murphy DL (2003). Brain region-specific alterations of 5-HT2A and 5-HT2C receptors in serotonin transporter knockout mice. J Neurochem 84: 1256-1265.

Line SJ, Barkus C, Rawlings N, Jennings K, McHugh S, Sharp T et al (2014). Reduced sensitivity to both positive and negative reinforcement in mice over-expressing the 5-hydroxytryptamine transporter. Eur J Neurosci 40: 3735-3745.

Lundberg J, Borg J, Halldin C, Farde L (2007). A PET study on regional coexpression of 5-HT1A receptors and 5-HTT in the human brain. Psychopharmacology (Berl) 195: 425-433.

Manko M, Bienvenu TCM, Dalezios Y, Capogna M (2012). Neurogliaform cells of amygdala: a source of slow phasic inhibition in the basolateral complex. J Physiol 590: 5611-5627.

Marek GJ, Martin-Ruiz R, Abo A, Artigas F (2005). The selective 5-HT2A receptor antagonist M100907 enhances antidepressantlike behavioral effects of the SSRI fluoxetine. Neuropsychopharmacology 30: 2205-2215.

Mascagni F, McDonald AJ (2007). A novel subpopulation of 5-HT type $3 \mathrm{~A}$ receptor subunit immunoreactive interneurons in the rat basolateral amygdala. Neuroscience 144: 1015-1024.

McDonald AJ, Mascagni F (2001). Colocalization of calciumbinding proteins and GABA in neurons of the rat basolateral amygdala. Neuroscience 105: 681-693.

McDonald AJ, Mascagni F (2007). Neuronal localization of 5-HT type $2 \mathrm{~A}$ receptor immunoreactivity in the rat basolateral amygdala. Neuroscience 146: 306-320. 
Murphy SE, Norbury R, Godlewska BR, Cowen PJ, Mannie ZM, Harmer CJ et al (2013). The effect of the serotonin transporter polymorphism (5-HTTLPR) on amygdala function: a metaanalysis. Mol Psychiatry 18: 512-520.

Narayanan V, Heiming RS, Jansen F, Lesting J, Sachser N, Pape H-C et al (2011). Social defeat: impact on fear extinction and amygdala-prefrontal cortical theta synchrony in 5-HTT deficient mice. PLoS One 6: e22600.

Pezawas L, Meyer-Lindenberg A, Drabant EM, Verchinski B a, Munoz KE, Kolachana BS et al (2005). 5-HTTLPR polymorphism impacts human cingulate-amygdala interactions: a genetic susceptibility mechanism for depression. Nat Neurosci 8: 828-834.

Popescu AT, Paré D (2011). Synaptic interactions underlying synchronized inhibition in the basal amygdala: evidence for existence of two types of projection cells. J Neurophysiol 105: 687-696.

Rainnie DG (1999). Serotonergic modulation of neurotransmission in the rat basolateral amygdala. J Neurophysiol 82: 69-85.

Richmond MA, Murphy CA, Pouzet B, Schmid P, Rawlins JNP, Feldon J (1998). A computer controlled analysis of freezing behaviour. J Neurosci Methods 86: 91-99.

Ryan SJ, Ehrlich DE, Jasnow AM, Daftary S, Madsen TE, Rainnie DG (2012). Spike-timing precision and neuronal synchrony are enhanced by an interaction between synaptic inhibition and membrane oscillations in the amygdala. PLoS One 7: e35320.

Sarkar A, Chachra P, Vaidya VA (2013). Postnatal fluoxetineevoked anxiety is prevented by concomitant 5-HT2A/C receptor blockade and mimicked by postnatal 5-HT2A/C receptor stimulation. Biol Psychiatry 76: 858-868.

Sosulina L, Meis S, Seifert G, Steinhäuser C, Pape H-C (2006). Classification of projection neurons and interneurons in the rat lateral amygdala based upon cluster analysis. Mol Cell Neurosci 33: $57-67$.

Spannuth BM, Hale MW, Evans AK, Lukkes JL, Campeau S, Lowry CA (2011). Investigation of a central nucleus of the amygdala/dorsal raphe nucleus serotonergic circuit implicated in fear-potentiated startle. Neuroscience 179: 104-119.

Uher R, McGuffin P (2010). The moderation by the serotonin transporter gene of environmental adversity in the etiology of depression: 2009 update. Mol Psychiatry 15: 18-22.

Wellman CL, Izquierdo A, Garrett JE, Martin KP, Carroll J, Millstein $\mathrm{R}$ et al (2007). Impaired stress-coping and fear extinction and abnormal corticolimbic morphology in serotonin transporter knock-out mice. J Neurosci 27: 684-691.

Wolff SBE, Gründemann J, Tovote P, Krabbe S, Jacobson G a, Müller C et al (2014). Amygdala interneuron subtypes control fear learning through disinhibition. Nature 509: 453-458.

Woodruff AR, Sah P (2007). Inhibition and synchronization of basal amygdala principal neuron spiking by parvalbumin-positive interneurons. J Neurophysiol 98: 2956-2961.

Zanoveli JM, Carvalho MC, Cunha JM, Brandão ML (2009). Extracellular serotonin level in the basolateral nucleus of the amygdala and dorsal periaqueductal gray under unconditioned and conditioned fear states: an in vivo microdialysis study. Brain Res 1294: 106-115.

Supplementary Information accompanies the paper on the Neuropsychopharmacology website (http://www.nature.com/npp) 